\title{
Anticytoskeletal Autoantibody to Microfilament Anchorage Sites Recognizes Novel Focal Contact Proteins
}

\author{
Jean-Luc Senécal, Sylvie Fortin, André Roussin, and France Joyal \\ Rheumatic Disease Unit and Division of Vascular Medicine, Notre-Dame Hospital, Department of Medicine, University of Montreal \\ School of Medicine, Montreal, Quebec, Canada H2L $4 K 8$
}

\begin{abstract}
Actin microfilaments are anchored to the plasma membrane at focal contacts. Using an indirect immunofluorescence method, we detected an autoantibody reactive with focal contacts in

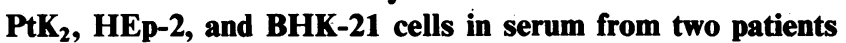
with early systemic sclerosis. With double immunofluorescence, using the actin-binding drug phalloidin, we localized the plaques decorated by these sera specifically at the termini of microfilament bundles. The reactive antigens were identified by immunoblotting as proteins of $80,000-$ and $75,300-\mathrm{mol}$ wt in PtK $\mathrm{P}_{2}$, and of 53,500-mol wt in HEp-2 and BHK-21 cells. The 53,500-mol wt protein was also identified in rat skeletal, myocardial, and smooth muscle tissues. The detergent solubility of these proteins suggested that they may be linked to the plasma membrane. The autoantigens were immunologically distinct from vinculin and $\alpha$-actinin, two major proteins also known to be concentrated at the ends of microfilament bundles. Our observations suggest that this novel anticytoskeletal autoantibody may identify a novel family of vertebrate cell proteins involved in the linkage of microfilaments to the plasma membrane at focal contacts.
\end{abstract}

\section{Introduction}

The cytoskeleton is a complex network of protein filaments in eukaryotic cells. Three distinct classes of cytoskeletal filaments are organized in the cytomatrix: microfilaments (MF), ${ }^{1}$ intermediate filaments, and microtubules. Each filamentous protein is associated with a range of accessory proteins that serve to stabilize filaments, to bridge adjacent filaments, and to link filaments to organelles or to the plasma membrane (1-3). The cytoskeleton controls cell motility and shape, membrane functions, and organelle distribution (4, 5). Anticytoskeletal autoantibodies are thus a wide range of immunoglobulins that react with cytoskeletal antigens (6).

The major protein subunit of MF is actin. In cultured epi-

Address reprint requests to Jean-Luc Senécal, M.D., RheumatologyImmunology Research Laboratory, Rheumatic Disease Unit, NotreDame Hospital, 1560 Sherbrooke St. East, Montreal, Quebec, Canada H2L 4K8. 1987.

Received for publication 29 April 1986 and in revised form 6 April

1. Abbreviations used in this paper: ANA, antinuclear antibody; FITC, fluorescein isothiocyanate; MF, microfilament; MFAS, MF anchorage sites.

J. Clin. Invest.

(C) The American Society for Clinical Investigation, Inc.

0021-9738/87/09/0778/08 \$2.00

Volume 80, September 1987, 778-785 thelial cells and in fibroblasts, actin filaments are organized in parallel bundles of stress fibers on the ventral cellular surface $(7,8)$. Actin filaments form, together with myosin, the various contractile systems responsible for cell motility (9). To exert a mechanical force for motility, this contractile assembly must be anchored to other cellular components. Membrane-protein linkages are thought to provide the necessary fixed points for converting mechanical stress produced by contractile proteins into useful work and hence are essential for muscle contraction, cytokinesis, cell motility and attachment of cells to surfaces (10). Thus many actin filaments are anchored to cell membranes. The areas where stress fibers terminate at specialized regions of the plasma membrane are known as focal contacts or adhesion plaques (11). Focal contacts are the sites of cell-to-substratum adhesion and typically form at the leading edge of a locomoting cell (12).

In nonmuscle cells, different proteins have been found to be concentrated at the ends of actin MF bundles at focal contacts. These include the two major actin-associating cytoskeletal proteins $\alpha$-actinin (mol wt 100,000-105,000) (8, 13-15) and vinculin (mol wt 130,000) (16). Roles in linking actin to the plasma membrane have been suggested for these proteins and recently reviewed (17). However one of the most important gaps in the understanding of the structural organization of the cytoplasm remains the nature of this linkage of the MF network to the plasma membrane (18). To further this understanding, the necessity of discovering new proteins has been recently emphasized $(9,15,16)$.

We have used previously indirect immunofluorescence microscopy and immunoblot analysis to identify anticytoskeletal autoantibodies in human sera $(6,19-21)$. In the course of a study of these antibodies in sera from patients with rheumatic diseases, we have identified a novel anticytoskeletal autoantibody that reacts with MF anchorage sites (MFAS). The autoantigens reactive with anti-MFAS have been characterized as distinct from $\alpha$-actinin and vinculin and appear to be novel anchorage proteins.

\section{Methods}

Patients J.R. and J.C.L. The index serum was obtained from patient J.R., a 45-yr-old white woman who was first evaluated by us in June 1984 for Raynaud's phenomenon of 13-yr duration. Physical examination revealed sclerodactyly. Capillary nailfold microscopy was within normal limits. The hemoglobin, leukocyte, and platelet counts, sedimentation rate, urinary analysis, serum creatinine, and creatine kinase were normal. Pulmonary function tests revealed a restrictive defect. An oesophagogram, roentgenograms of the hands and chest, and an electrocardiogram disclosed no abnormality. The rheumatoid factor was negative. Antinuclear antibodies (ANA) were not detected using rat liver as substrate. Anticentromere antibodies were not detected on HEp-2 cells. Anti-Scl 70 was absent by Ouchterlony immunodiffusion. Precipitating antibodies to Ro, La, nRNP, and Sm antigens were absent by counterimmunoelectrophoresis. The second serum was ob- 
tained from patient J.C.L., a 58-yr-old white female seen in June 1985 for Raynaud's phenomenon of 24-yr duration. Physical examination revealed digital, facial, and lingual telangiectases. Capillary nailfold microscopy disclosed capillary dilatations and avascular areas. Laboratory tests were performed as above and were negative except for the following. Pulmonary function tests revealed a restrictive defect. The diffusion capacity was $60 \%$ of the predicted value. ANA were positive in a titer of $1: 160$ with a diffuse pattern.

Other patients. Frozen serum aliquots $\left(-80^{\circ} \mathrm{C}\right)$ were from 57 normal controls and from 24 systemic sclerosis, 30 definite or classical rheumatoid arthritis, and 32 systemic lupus erythematosus patients who fulfilled established American Rheumatism Association disease criteria and were followed at the Connective Tissue Diseases Clinic of the hospital. Sera from 103 patients without connective tissue diseases were also studied ( 34 osteoarthritis, 29 gout, 22 ankylosing spondylitis, and 18 psoriatic arthritis).

Cell lines. $\mathrm{PtK}_{2}$ (CCL 56) derived from rat kangaroo kidney epithelium, HEp-2 (CCL 83) derived from a human laryngeal epidermoid carcinoma, and BHK-21 (CCL 10) fibroblastlike cells derived from baby hamster kidney were from the American Type Culture Collection, Rockville, MD. PtK $_{2}$ cells were grown in RPMI medium 1640 supplemented with $10 \%$ fetal bovine serum in a $5 \% \mathrm{CO}_{2}$ atmosphere at $37^{\circ} \mathrm{C}$ in an incubator.

Antibodies, cytoskeletal proteins, and phalloidin. Human platelet vinculin and rabbit anti-chicken vinculin were a generous gift from Dr. K. Burridge, Department of Anatomy, University of North Carolina at Chapel Hill $(17,22)$, who also provided chicken gizzard $\alpha$-actinin and rabbit anti-beef heart $\alpha$-actinin $(13,23)$. Fluorescein- or rhodamine-conjugated phalloidin, a highly specific filamentous actin MF binding alkaloid derived from the mushroom Amanita phalloides (24), was from Molecular Probes Inc., Junction City, OR. Mouse monoclonal anti-actin and anti-cytokeratin 8 antibodies were from Amersham Corp., Arlington Heights, IL.

Indirect immunofluorescence. Subconfluent monolayers of $\mathrm{PtK}_{2}$, HEp-2, or BHK-21 cells grown on 18-mm glass coverslips were permeabilized and fixed with $\mathbf{0 . 0 0 5 \%}$ digitonin (Anachemia) in $2 \%$ formaldehyde for 2.5 or $5 \mathrm{~min}$ at $37^{\circ} \mathrm{C}(6,21)$. Alternatively, cells were fixed in $2 \%$ formaldehyde for $5 \mathrm{~min}$ followed by permeabilization with $0.1 \%$ Triton $\mathrm{X}-100$ for $4 \mathrm{~min}$. The coverslips were then incubated for $30 \mathrm{~min}$ at $37^{\circ} \mathrm{C}$ with serum from the index patient, from other patients, or with anticytoskeletal antibodies at a final dilution of 1:20. The cells were further incubated $(30 \mathrm{~min})$ with fluorescein isothiocyanate (FITC)-conjugated goat anti-human IgG or anti-human IgM or with goat anti-rabbit IgG (Cappel Laboratories, Cochranville, PA). The fluorescein-to-protein molar ratio of these antibodies ranged from 1.46 to 1.78 . In other experiments, fixation was followed by a single incubation step with fluorescein phalloidin (1:24). In double-labeling experiments, the cells were incubated with the index serum for $30 \mathrm{~min}$, followed by incubation with FITC goat anti-human IgG and further incubation with rhodamine phalloidin (1:20) for $30 \mathrm{~min}$. The coverslips were mounted face down in $50 \%$ glycerol on glass slides and observed in a photomicroscope III (Carl Zeiss, Inc., Thornwood, NY) equipped with an HB50 high-pressure mercury lamp and a III RS epifluorescence condenser. Indirect immunofluorescence was also performed on different commercially prepared HEp- 2 monolayers, using the reactives supplied in the kits as recommended by the manufacturer (Antibodies Inc., Davis, CA; ImmunoConcepts, Sacramento, CA).

Preparation of cells, cytoskeletal extracts, and tissues for electrophoresis. $\mathrm{PtK}_{2}$ cells were washed with phosphate-buffered saline (PBS) containing a mixture of protease inhibitors $(2.5 \mathrm{mg} / \mathrm{ml}$ leupeptin, 2.5 $\mathrm{mg} / \mathrm{ml}$ aprotinin, $100 \mathrm{mM}$ benzamidine, $50 \mathrm{mM}$ phenylmethylsulfonyl fluoride [PMSF], and $1.0 \mathrm{mg} / \mathrm{ml}$ pepstatin) diluted 100 -fold (25). The cells were scraped off the culture flasks with a rubber policeman and immediately immersed in the boiling mix for gel electrophoresis. In other experiments, trypsinized PtK ${ }_{2}$, HEp-2, or BHK-21 cells were precipitated $\left(500 \mathrm{~g}, 3 \mathrm{~min}, 4^{\circ} \mathrm{C}\right)$ in isotonic PBS, and cytoskeletal extracts were prepared by further resuspending the pellet at $4^{\circ} \mathrm{C}$ in $9 \mathrm{ml}$ of a lysing solution designed to preserve the cytoskeleton $(26,27): 0.05$ $\mathrm{M} \mathrm{NaCl}, 0.01 \mathrm{M}$ Hepes-KOH (Boehringer Mannheim Diagnostics, Inc., Houston, TX), $2.5 \mathrm{mM} \mathrm{MgCl}, 0.3 \mathrm{M}$ sucrose, and $0.01 \mathrm{mM}$ PMSF. Triton X-100 (Sigma Chemical Co., St. Louis, MO) was added to a final concentration of $0.5,0.1$, or $0.05 \%$. After mixing the detergent by gentle swirling for $45 \mathrm{~s}$ at ambient temperature, the extracted cytoskeletons were precipitated by centrifugation $\left(250 \mathrm{~g}, 5 \mathrm{~min}, 4^{\circ} \mathrm{C}\right)$ and washed in $5 \mathrm{ml}$ of lysing solution. For preparation of tissues, fasting Sprague-Dawley rats were sacrificed and $1 \mathrm{~cm}^{2}$ of dissected muscle tissue from heart ventricle, psoas, and stomach was immediately removed and immersed in $\mathrm{PBS}\left(4^{\circ} \mathrm{C}\right)$ with the same protease inhibitors as above. The samples were homogenized with a Polytron and frozen at $-80^{\circ} \mathrm{C}$ until use.

Gel electrophoresis and electrophoretic blotting procedure. Sodium dodecyl sulfate-polyacrylamide gel electrophoresis (SDS-PAGE) was performed according to Laemmli (28), using a 4\% stacking gel. A 5-12\% gradient of acrylamide (Bio-Rad Laboratories, Richmond, CA) was used in the separation gel. $25 \mu \mathrm{g}$ of total proteins from cytoskeletal extracts, or whole cells, or $0.25 \mu \mathrm{g}$ of chicken gizzard $\alpha$-actinin or 0.125 $\mu \mathrm{g}$ of human platelet vinculin were added to each well. $25 \mu \mathrm{g}$ of muscle proteins from rat stomach or ventricle and $40 \mu \mathrm{g}$ of striated muscle were also used. Proteins were transferred to a nitrocellulose sheet according to Towbin et al. (29).

Immunodetection of proteins on nitrocellulose. The electrophoretic blots were saturated with $0.5 \%$ casein in saline $(0.9 \% \mathrm{NaCl}, 10 \mathrm{mM}$ Tris- $\mathrm{HCl}, \mathrm{pH} \mathrm{7.4)}$ for $60 \mathrm{~min}$ at $37^{\circ} \mathrm{C}$. The sheets were incubated $(3 \mathrm{~h}$, $37^{\circ} \mathrm{C}$ ) on a rocker with patient J.R. or J.C.L. serum (1:80), anti- $\alpha$-actinin (1:75), antivinculin (1:500), or antiactin (1:400) in PBS- $-0.5 \%$ casein, pH 7.4, for a total volume of $5 \mathrm{ml}$. The blots were further incubated $\left(75 \mathrm{~min}, 37^{\circ} \mathrm{C}\right)$ with peroxidase-conjugated goat antihuman IgG (1:250), goat anti-rabbit IgG (1:250) (Cappel Laboratories) or sheep anti-mouse immunoglobulins (1:250) (Amersham Corp.).

\section{Results}

Indirect immunofluorescence observation and characterization of an antibody to MFAS in PtK $\mathrm{K}_{2}$ cells. Serum from patients J.R. and J.C.L. contained an antibody reactive with linear plaques localized within the cytoplasm or at its periphery (Fig. 1). The plaques were observed predominantly in nonconfluent cells where they were more numerous along the leading edge of cell growth. The plaques were also observed within the cytoplasm in a parallel distribution reminiscent of the parallel organization of actin MF bundles in epithelial cells. The morphology of these plaques was closely similar to that reported for focal contacts $(11,12,17)$. With careful up and down focusing, these plaques were present on the ventral cellular surface where focal contacts are also localized. In addition to the much more prominent staining of these plaques, a faint linear and periodic staining was also occasionally observed in the cytoplasm of some cells. The distribution of fluorescence associated with these sera was revealed only when indirect immunofluorescence was performed on detergent permeabilized cells. Labeling was absent when the digitonin permeabilization step was omitted, indicating that the antigen recognized by these sera was not exposed on the cell surface. Labeling was critically dependent on the duration of permeabilization with digitonin: the intensity of labeling was optimal at $2.5 \mathrm{~min}$ but decreased at $5 \mathrm{~min}$. Other cytoskeletal components were not stained by J.R. serum, whereas J.C.L. serum reacted with intermediate filaments.

These observations suggested a structural relationship between the antigen(s) reactive with these sera and actin MF. Analysis of the cytoskeletal localization of the antigen recog- 

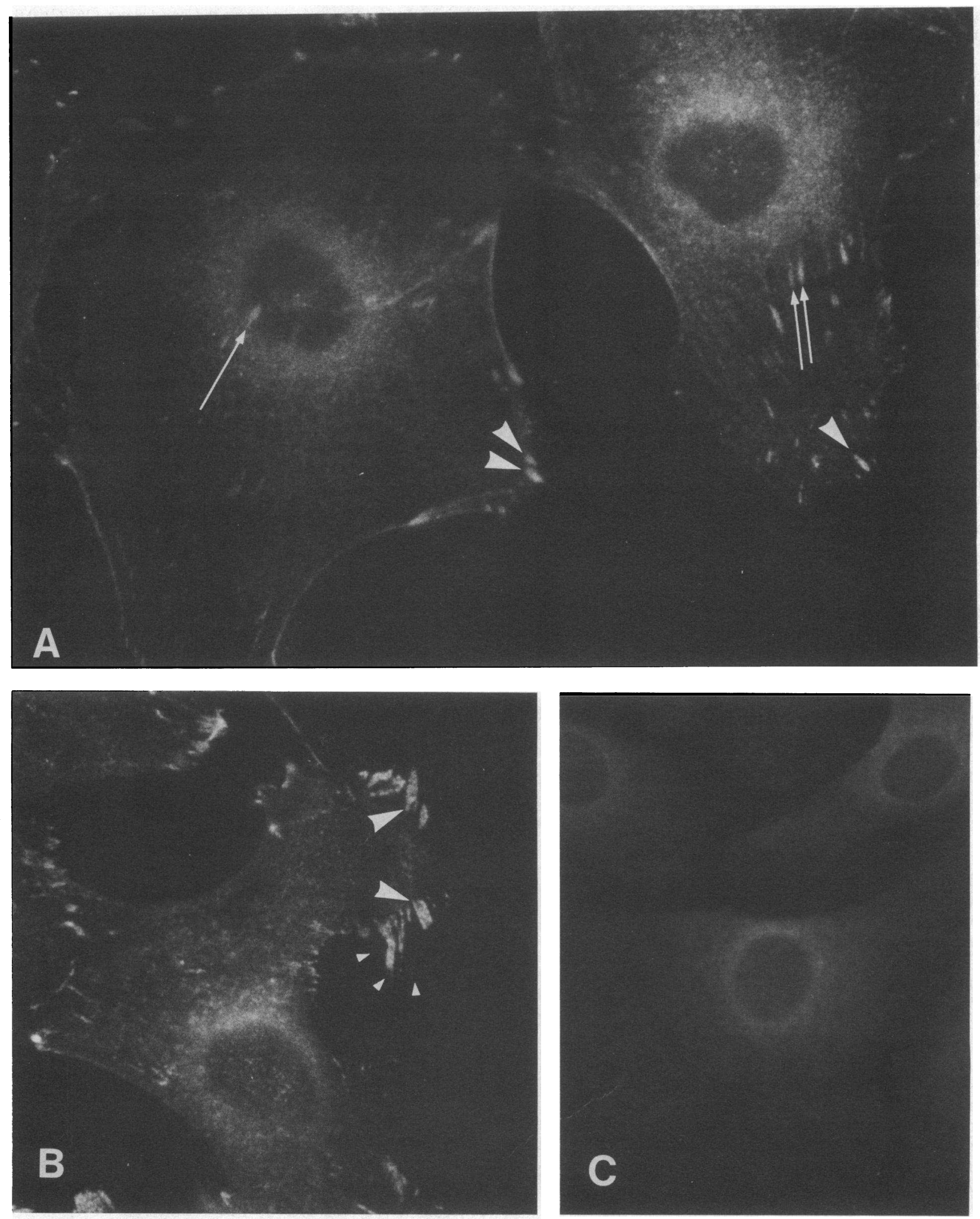

Figure 1. Fluorescent pattern produced by serum from patient J.R. in $\mathrm{PtK}_{2}$ cells. $(A)$ Linear cytoplasmic plaques have been decorated by J.R. serum. The plaques are localized at the periphery of the cytoplasm along the leading edge of cell growth (arrowheads). The plaques are also localized within the cytoplasm, often in a parallel distribution reminiscent of the parallel organization of actin microfilaments in epithelial cells (parallel arrows). Another plaque is localized on the ventral nuclear surface (single arrow). Other cytoskeletal

components have not been stained $(1,500 \times)$. (B) In growing cells J.R. serum stained predominantly plaques localized along the leading edge of cell growth (large arrowheads). The plaques were of a morphology closely similar to focal contacts. Note that the plaques do not extend beyond the plasma membrane (outlined by small arrowheads) $(1,500 \times)$. (C) With serum from a normal human control, specific fluorescence was absent $(600 \times)$. 
nized by these sera in relation to MF was performed with double immunofluorescence. The reactive antigenic sites were localized specifically at the termini of MF bundles (Fig. 2).

MFAS labeling by J.R. and J.C.L. sera was readily observed to a dilution of $1: 400$ and 1:200, respectively. The autoantibody istotype was IgG.

Indirect immunofluorescence detection of anti-MFAS in other cell lines. The antigen recognized by the autoantibodies was also detected in HEp-2 and BHK-21 cells, where it localized in linear plaques along the leading edge of cell growth. As in the case of $\mathrm{PtK}_{2}$ cells, this pattern was observed in cells permeabilized with digitonin and was also visualized when cells were alternatively permeabilized with Triton X-100 (Fig. 3). The pattern produced by J.R. serum was not detected however when commercially prepared (methanol-fixed) HEp-2

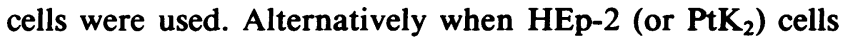
grown by us were permeabilized with $0.1 \%$ Triton $\mathrm{X}-100$ $\left(37^{\circ} \mathrm{C}, 1 \mathrm{~min}\right)$, fixed with methanol $\left(-10^{\circ} \mathrm{C}, 5 \mathrm{~min}\right)$, and used as substrate, staining was absent, indicating inadequate antigen preservation with these fixation methods.

Characterization by immunoelectrophoresis of the antigenic specificity of anti-MFAS. SDS-gel electrophoretograms of whole $\mathrm{PtK}_{2}$ cells were examined for proteins that bound J.R. and J.C.L. sera and could be visualized with peroxidase antihuman IgG. The sera recognized two protein bands of 80,000 and 75,300 mol wt, respectively (Fig. 4). These bands were both observed with the cell preparation treated with a mixture of protease inhibitors and that treated with PMSF only. J.C.L. serum also reacted with a 55,000-mol wt protein corresponding to a cytokeratin, as identified by a monoclonal anticytokeratin antibody (not shown). In $\mathrm{PtK}_{2}$ Triton cytoskeletal extracts, preservation of the 80,000 - and 75,300-mol wt proteins was dependent on detergent concentration. The proteins were solubilized at a Triton concentration of $0.5 \%$ and less soluble at lower $(0.05 \%)$ Triton concentration. Although removal was apparent with increasing detergent concentration, the 80,000- mol wt protein was preserved irrespective of the detergent concentration used, whereas the $75,300-\mathrm{mol}$ wt protein was more soluble. In whole HEp-2 and BHK-21 cells, J.R. serum recognized a single protein band of 53,500 mol wt. In HEp-2 and BHK-21 Triton cytoskeletal extracts, the solubility pattern of this protein was similar to that observed for the $\mathbf{P t K}_{2}$ 80,000-mol wt protein.

The 53,500-mol wt protein was also identified in rat muscle tissues (Fig. 5). In addition a 26,500-mol wt reactive protein was also noted in striated skeletal and heart muscle tissues.

Differentiation of the autoantigens reactive with anti$M F A S$ from vinculin and $\alpha$-actinin. With immunoblot analysis, the anti-MFAS reactive autoantigens were distinct from vinculin and $\alpha$-actinin (Fig. 6). SDS-polyacrylamide gel electrophoretograms of human platelet vinculin or chicken gizzard $\alpha$-actinin revealed protein bands of 130,000 and 102,000 mol wt, respectively. The $130,000-$ mol wt protein was reactive with a rabbit antibody to vinculin, and this antibody also reacted with a $130,000-$ mol wt protein in whole $\mathrm{PtK}_{2}$ cells. Similarly, the $102,000-$ mol wt protein was reactive with a rabbit antibody to $\alpha$-actinin, and this antibody also reacted with a 102,000-mol wt protein band in whole PtK $_{2}$ cells. This confirmed the presence of vinculin and $\alpha$-actinin in this cell line $(30,31)$. In whole $\mathrm{PtK}_{2}$ cells, however, the bands reactive with anti-MFAS were distinct from vinculin and $\alpha$-actinin. AntiMFAS did not react with purified vinculin or $\alpha$-actinin. AntiMFAS also did not react with the 42,000-mol wt actin band identified in $\mathrm{PtK}_{2}, \mathrm{HEp}-2$, and BHK-21 cell lines with a monoclonal anti-actin antibody (not shown).

Longitudinal study. Anti-MFAS antibodies were present in four J.R. and J.C.L. sera collected over 22 and 12 mo, respectively, during which the clinical status did not change.

Other sera. Anti-MFAS was not found by indirect immunofluorescence in sera from normal controls, connective tissue disease patients, or from patients with other rheumatic diseases.

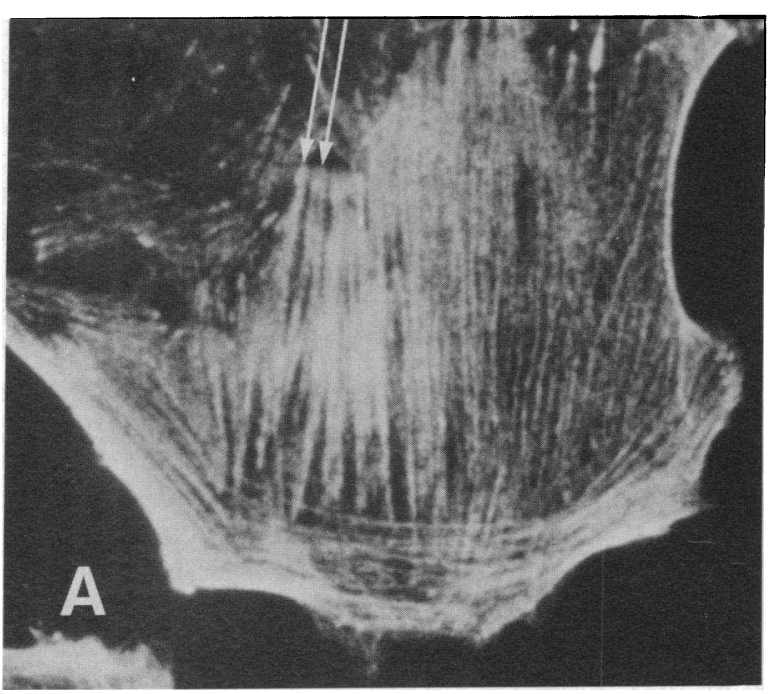

Figure 2. Double immunofluorescence cytoskeletal localization of the PtK $\mathrm{P}_{2}$ antigenic sites recognized by patient J.R. serum. $(A)$ Rhodamine phalloidin has decorated cytoplasmic bundles of microfilaments (arrows). (B) After incubation with J.R. serum followed by in-

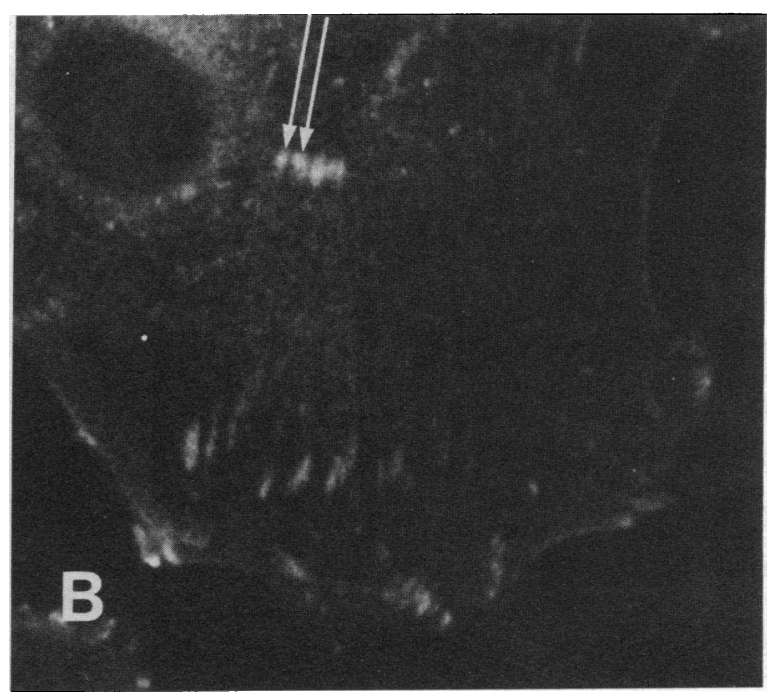

cubation with FITC goat anti-human IgG, this micrograph of the same field as in $\boldsymbol{A}$ was obtained with the fluorescein optical channel. J.R. serum has stained an antigen localized at the termini of microfilament bundles. Arrows indicate the same locations as in $A(2,200 \times)$. 

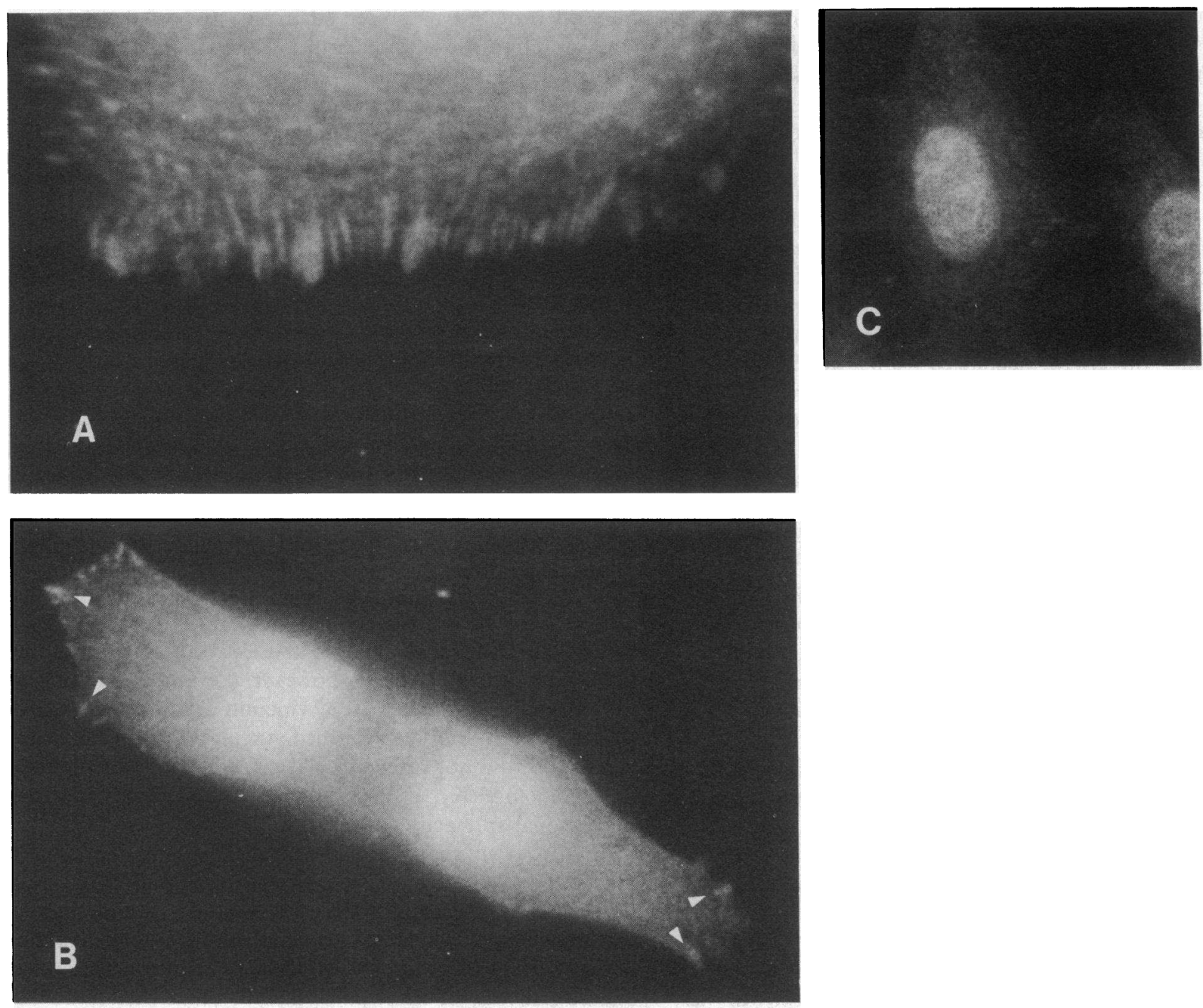

Figure 3. Fluorescent pattern produced in HEp-2 cells by an autoantibody to microfilament anchorage sites. $(A)$ This high-magnification micrograph of the leading edge of an interphase cell shows labeling of adhesion plaques and of the parallel termini of microfilament bundles $(2,200 \times)$. (B) Autoantibody has labeled plaques in two

\section{Discussion}

We have described a novel autoantibody reactive with proteins associated with the termini of MF. A role in MF anchorage for the autoantigens reactive with this antibody is consistent with (a) their predominant localization at the termini of stress fibers and along the leading edge of cell growth or motility, where MF bundles terminate, $(b)$ the similarity between the pattern produced by this antibody and the morphology of focal contacts, where MF are anchored, and (c) the predominant expression of the autoantigens in cultured cells that are not confluent and hence can grow and locomote. We have therefore named this autoantibody anti-MFAS.

The antigens reactive with anti-MFAS were identified as proteins of 80,000 and 75,300 mol wt in whole PtK $_{2}$ cells. Because the 75,300- and 80,000-mol wt proteins were preserved when five protease inhibitors were used in the cell preparation procedure, it is unlikely that they are the split products of a single protein. In whole HEp- 2 and BHK-21 cells, and also daughter cells during cytokinesis (arrowheads). Note that the plaques are strikingly localized at the opposite poles of the anchored daughter cells $(1,500 \times) .(C)$ Normal human serum does not react with anchorage sites $(960 \times)$.

in skeletal, myocardial, and smooth muscle tissues a 53,500mol wt protein was the antigen reactive with anti-MFAS. In cytoskeletal extracts the detergent solubility of these proteins was similar and characterized by increasing solubilization at increasing Triton X-100 concentration. Because detergents characteristically solubilize the components of biological membranes (32), the solubility pattern of these anti-MFAS reactive proteins suggests that they may be linked to the intracellular surface of the plasma membrane. Our observation with indirect immunofluorescence in which MFAS labeling was critically dependent on the duration of permeabilization with digitonin is also consistent with this, as time is a factor in controlling the degree of cell membrane extraction by detergents (33). This is also supported by the absence of autoantigens from the external cell surface.

Using immunoblotting, purified vinculin and $\alpha$-actinin, and specific antibodies to these proteins, we have further shown that the anti-MFAS reactive autoantigens are distinct from vinculin and $\alpha$-actinin. Our data suggest that they are 

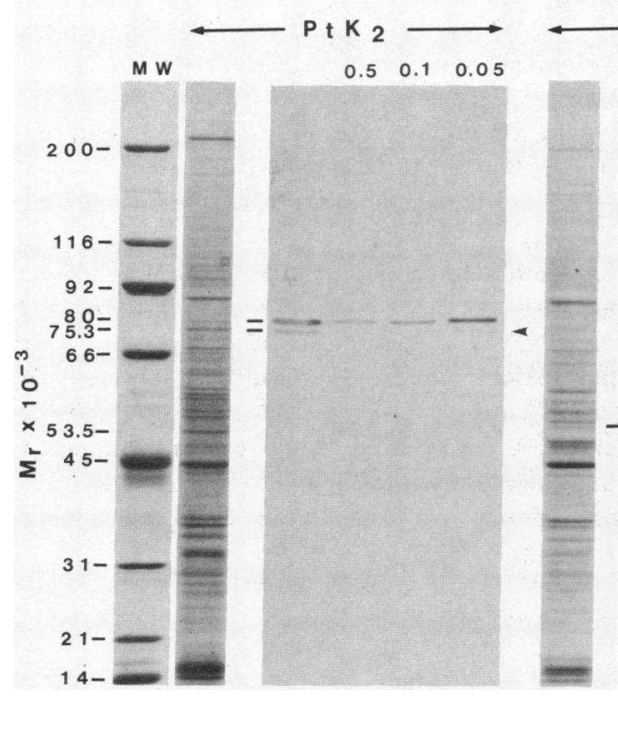

A

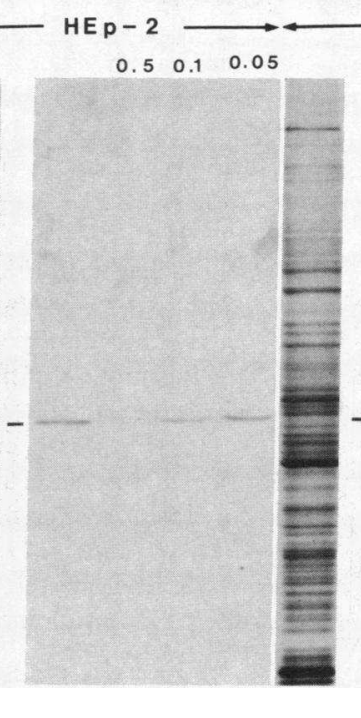

G

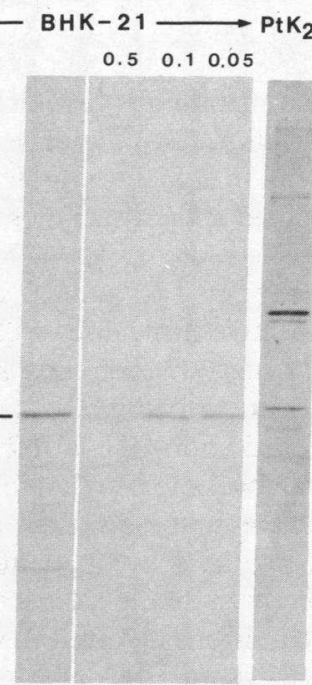

$\begin{array}{llll}\mathbf{N} & \mathbf{P} & \mathbf{Q}\end{array}$
Figure 4. Identification of the antigens reactive with antibodies to $\mathrm{mi}$ crofilament anchorage sites. Lanes $A, B, G$, and $L$ are Coomassie Bluestained SDS-polyacrylamide gels of molecular weight markers, whole PtK $_{2}$, HEp2, and BHK-21 cells. The other lanes are blots obtained from parallel gels and incubated with patient serum followed by incubation with peroxidase-congugated goat anti-human IgG. Numbers at the top indicate the concentration of Triton X-100 used in the preparation of cytoskeletal extracts. (C) Reaction of J.R. serum with whole $\mathrm{PtK}_{2}$ cells, showing labeling of two bands of 80,000 - and 75,300mol wt (bars). Lanes $D-F$ show that these two proteins are detergent soluble. The 75,300-mol wt protein was completely solubilized at higher

detergent concentrations $(D$ and $E$ ) but note that in the extract prepared with the lower Triton concentration the protein was again faintly visualized $(F$, arrowhead). $(H)$ reaction of J.R. serum with a protein band of 53,500 mol wt in whole HEp- 2 cells $($ bar $)$. Lanes $I-K$ show that the detergent solubility of the $53,500-$ mol wt protein reactive with J.R. serum is similar to the PtK $\mathrm{K}_{2} 80,000-$ mol wt protein. $(M)$ reaction of J.R. serum with a protein band of $53,500 \mathrm{~mol}$ wt in whole BHK-21 cells (bar). Lanes $N-P$ show that the detergent solubility of this protein is similar to the HEp-2 53,500-mol wt protein. $Q$, reaction of J.C.L. serum with bands of 80,000 and 75,300-mol wt in whole PtK ${ }_{2}$ cells, and with a cytokeratin. (See Results for details.)

novel proteins based on the absence of reactivity of the autoantibody with purified vinculin and $\alpha$-actinin, its lack of reactivity with $\mathrm{PtK}_{2}$ cell vinculin and $\alpha$-actinin, and their molecular weight, which is distinct from the molecular weight of other proteins concentrated at the ends of MF bundles (10).

Reactivity of anti-MFAS with the human, hamster, rat, and marsupial tissues tested shows that these proteins are present in a variety of vertebrate cells. Our data suggest that a new family of proteins involved in MF-to-plasma membrane linkage in vertebrate cells may have been identified, which share $(a)$ the same cellular distribution at the termini of stress

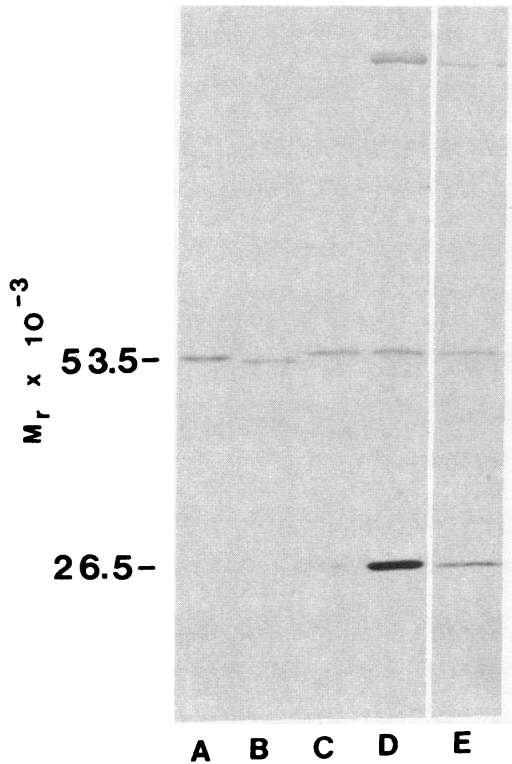

Figure 5. Identification of the 53,500-mol wt protein in rat muscle tissues. This immunoblot shows that the 53,500 -mol wt protein reactive with J.R. serum in HEp-2 $(A)$ and BHK-21 cells $(B)$, is also present in stomach $(C)$, myocardium $(D)$, and skeletal muscle $(E)$. $D$ and $E$ also show the reactivity of J.R. serum with a $26,500-$ mol wt protein.
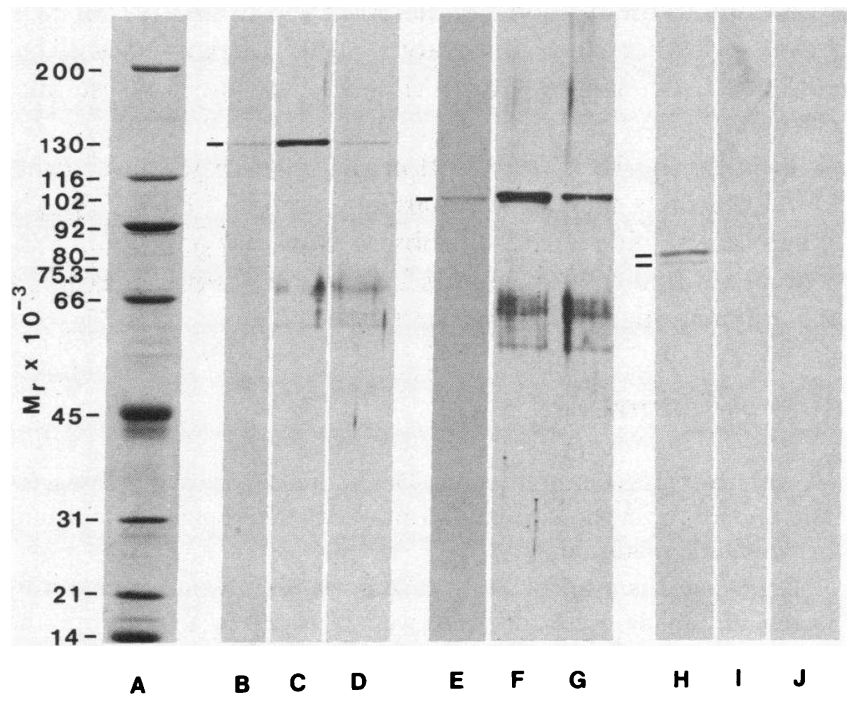

Figure 6. The antigens reactive with an antibody to microfilament anchorage sites are distinct by immunoblotting from vinculin and $\alpha$ actinin. Lanes $A, B$, and $E$ are Coomassie Blue-stained SDS-polyacrylamide gels. The other lanes are blots. $(A)$ Molecular weight markers. $(B)$ Human platelet vinculin, showing a band of 130,000 mol wt (bar). (C) Reaction of rabbit antivinculin with purified human platelet vinculin and $(D)$ with a $130,000-$ mol wt protein in whole PtK $\mathrm{Pt}_{2}$ cells, showing the presence of vinculin in this cell line. $(E)$ Chicken gizzard $\alpha$-actinin, showing a band of $102,000 \mathrm{~mol} \mathrm{wt}$ (bar). $(F)$ Reaction of rabbit anti- $\alpha$-actinin with chicken gizzard $\alpha$ actinin and $(G)$ with a $102,000-$ mol wt protein in whole $\mathrm{PtK}_{2}$ cells, showing the presence of $\alpha$-actinin in this cell line. $(H)$ Reaction of J.R. serum with two protein bands of 80,000 and $75,300 \mathrm{~mol} \mathrm{wt} \mathrm{in}$ whole $\mathrm{PtK}_{2}$ cells (bars) but not with the 130,000 - or 102,000 -mol wt proteins. (I) Lack of reactivity of J.R. serum with human platelet vinculin or $(J)$ with chicken gizzard $\alpha$-actinin. 
fibers, $(b)$ a similar detergent solubility pattern, and (c) common epitope(s) reactive with anti-MFAS. As in the case of the attachment of actin to the erythrocyte membrane, in which a chain of proteins mediates this association (34), the proteins defined by anti-MFAS may form a link in a chain of proteins that includes vinculin (17) and is involved in the attachment of actin to the plasma membrane.

Although the clinical features of patients J.R. and J.C.L.'s disease did not meet established connective tissue disease classification criteria, they were strongly suggestive of early systemic sclerosis, a disease associated with autoantibodies (35). Anti-MFAS was not found in sera from 57 normal controls, 63 patients with systemic lupus erythematosus or rheumatoid arthritis, and 103 patients with other rheumatic diseases. The observation thus far of anti-MFAS in these two patients is intriguing in view of the occurrence in systemic sclerosis of other autoantibodies also directed to antigens involved in various aspects of cell movements. Microtubule organizing centers, which include kinetochores and centrosomes with their centrioles (36), are one such target for these autoantibodies. Anticentromere antibodies, which occur in the CREST (calcinosis, Raynaud's phenomenon, esophageal motility disorder, sclerodactyly, telangiectases) syndrome variant of systemic sclerosis (35), react specifically with kinetochore proteins $(37,38)$. Autoantibodies to centrioles and to centrosomes have also been described (39-41). In addition, we have previously reported in serum from a patient with CREST an autoantibody to the mitotic spindle poles and midbody $(20,21)$. However further study of a larger group of patients will be required to determine if anti-MFAS is specific for systemic sclerosis.

Finally, the lack of detection of anti-MFAS by routine ANA substrates such as commercially prepared HEp- 2 cells is in agreement with our recent observation that other anticytoskeletal antibodies may be missed with these substrates due to inadequate antigen preservation (6).

\section{Acknowledgments}

We wish to express our gratitude to Dr. André Dagenais for his suggestions and for reviewing the manuscript. We thank Micheline Bouchard for typing the manuscript.

Dr. Senécal is a recipient of an Associateship from the Arthritis Society of Canada. Research funds were provided by a grant from the Medical Research Council of Canada to Dr. Senécal.

\section{References}

1. Alberts, B., D. Bray, J. Lewis, M. Raff, K. Roberts, and J. D. Watson, editors. 1983. The cytoskeleton. In Molecular Biology of the Cell. Garland Publishing, New York, 549-610.

2. Pollard, T. D. 1984. Actin-binding protein evolution. Nature (Lond.). 312:403.

3. Wang, E. 1985. Intermediate filament associated proteins. Ann. N. Y. Acad. Sci. 455:32-56.

4. Weber, K., and M. Osborne. 1985. The molecules of the cell matrix. Sci. Am. 253:110-120.

5. Paulin, D. 1985. Les fonctions du cytosquelette. Médecine Sciences. 85:198-202.

6. Oliver, J. M., J.-L. Senécal, and N. F. Rothfield. 1985. Autoantibodies to the cytoskeleton in human sera. Cell Muscle Motil. 6:55-74.
7. Lazarides, E., and K. Weber. 1974. Actin antibody: the specific visualization of actin filaments in non-muscle cells. Proc. Natl. Acad. Sci. USA. 71:2268-2272.

8. Stossel, T. P. 1984. Contribution of actin to the structure of the cytoplasmic matrix. J. Cell Biol. 99:15s-21s.

9. Pollard, T. D. 1981. Cytoplasmic contractile proteins. J. Cell Biol. $91: 156 \mathrm{~s}-165 \mathrm{~s}$.

10. Geiger, B. 1983. Membrane-cytoskeleton interaction. Biochim. Biophys. Acta. 737:305-341.

11. Abercrombie, M., J. E. M. Heaysman, and S. M. Pegrum. 1971. The locomotion of fibroblasts in culture. IV. Electron microscopy of the leading lamella. Exp. Cell Res. 67:359-367.

12. Heath, J. P., and G. A. Dunn. 1978. Cell to substratum contacts of chick fibroblasts and their relation to the microfilament system. A correlated interference-reflexion and high-voltage electromicroscope study. J. Cell Sci. 29:197-212.

13. Lazarides, E., and K. Burridge. 1975. $\alpha$-Actinin: immunofluorescent localization of a muscle structural protein in nonmuscle cells. Cell 6:289-298.

14. Burridge, K., and L. McCullough. 1980. The association of $\alpha$-actinin with the plasma membrane. J. Supramol. Struct. 13:53-65.

15. Weeds, A. 1982. Actin-binding proteins: regulators of cell architecture and motility. Nature (Lond.). 296:811-816.

16. Geiger, B. 1979. A $130 \mathrm{~K}$ protein from chicken gizzard: its localization at the termini of microfilament bundles in cultured chicken cells. Cell. 18:193-206.

17. Mangeat, P., and K. Burridge. 1984. Actin-membrane interaction in fibroblasts: what proteins are involved in this association? $J$. Cell Biol. 99:95s-103s.

18. Korn, E. D. 1982. Actin polymerization and its regulation by proteins from nonmuscle cells. Physiol. Rev. 62:672-737.

19. Senécal, J.-L., N. F. Rothfield, and J. M. Oliver. 1982. Immunoglobulin $\mathbf{M}$ autoantibody to vimentin intermediate filaments. $J$. Clin. Invest. 69:716-721.

20. Oliver, J. M., P. R. Sager, J.-L. Senécal, and N. F. Rothfield. 1983. A mitosis-specific autoantibody in human serum. J. Cell Biol. 97:43a. (Abstr.)

21. Senécal, J.-L., J. M. Oliver, and N. F. Rothfield. 1985. Anticytoskeletal autoantibodies in the connective tissue diseases. Arthritis Rheum. 28:889-898.

22. Burridge, K., and J. Feramisco. 1980. Microinjection and localization of a $130 \mathrm{~K}$ protein in living fibroblasts: a relationship to actin and fibronectin. Cell. 19:587-595.

23. Burridge, K., and J. R. Feramisco. 1981. Non-muscle $\alpha$-actinins are calcium-sensitive actin-binding proteins. Nature (Lond.). 244:565-567.

24. Wulf, E., A. Deboden, F. A. Bantz, H. Faulstich, and T. Wieland. 1979. Fluorescent phallotoxin, a tool for the vizualisation of cellular actin. Proc. Natl. Acad. Sci. USA. 76:4498-4502.

25. Miake-Lye, R., and M. W. Kirschner. 1985. Induction of early mitotic events in a cell-free system. Cell. 41:165-175.

26. Lenk, R., and S. Penman. 1979. The cytoskeletal framework and poliovirus metabolism. Cell. 16:289-301.

27. Bibor-Hardy, V., A. Dagenais, and R. Simard. 1985. In situ localization of the major capsid protein during lytic infection by herpes simplex virus. J. Gen. Virol. 66:897-901.

28. Laemmli, U. K. 1970. Cleavage of structural proteins during the assembly of the head of bacteriophage T4. Nature (Lond.). 227:680-685.

29. Towbin, H., T. Staehelin, and J. Gordon. 1979. Electrophoretic transfer of proteins from polyacrylamide gels to nitrocellulose sheets. Proc. Natl. Acad. Sci. USA. 76:4350-4354.

30. Sanger, J. W., J. M. Sanger, and B. M. Jockush. 1983. Differences in the stress fibers between fibroblasts and epithelial cells. $J$. Cell Biol. 96:961-969.

31. Geiger, B. 1982. Microheterogeneity of avian and mammalian vinculin. J. Mol. Biol. 159:685-701. 
32. Helenius, A., and K. Simons. 1975. Solubilization of membranes by detergents. Biochim. Biophys. Acta. 415:29-79.

33. Jessen, K. R. 1983. Immunocytochemistry of cell and tissue cultures. In Immunocytochemistry: Practical Applications in Pathology and Biology. J. M. Polakan and S. Van Noorden, editors. John Wright PSG Inc., Littleton, MA. 169-183.

34. Branton, D., C. Cohen, and J. Tyler. 1981. Interaction of cytoskeletal proteins on the human red cell membrane. Cell. 24:24-32.

35. Tan, E. M., G. P. Rodnan, I. Gracia., Y. Moroi, M. J. Fritzler, and C. Peebles. 1980. Diversity of antinuclear antibodies in progressive systemic sclerosis. Arthritis Rheum. 23:617-625.

36. Brinkley, B. R. 1985. Microtubule organizing centers. Annu. Rev. Cell Biol. 1:145-172.

37. Earnshaw, W. C., N. Halligan, C. Cooke, and N. Rothfield.
1984. The kinetochore is part of the metaphase chromosome scaffold. J. Cell Biol. 98:352-357.

38. Hyams, J. S. 1984. Rheumatoid sera unravel microtubule organizers. Nature (Lond.). 308:604-605.

39. Osborn, T. G., J. S. Ryerse, N. E. Bauer, J. E. Urhahn, D. Blair, and T. L. Moore. 1986. Anticentriole antibody in a patient with progressive systemic sclerosis. Arthritis Rheum. 29:142-146.

40. Tufanelli, D. L., F. McKeon, D. M. Kleinsmith, T. K. Burnhamm, and M. Kirschner. 1983. Anticentromere and anticentriole antibodies in the scleroderma spectrum. Arch. Derm. 119:560-566.

41. Moroi, Y., I. Murata, A. Takeuchi, N. Kamatani, K. Tanimoto, and R.Yokohari. 1983. Human anticentriole autoantibody in patients with scleroderma and Raynaud's phenomenon. Clin. Immunol. Immunopathol. 29:381-390. 